\title{
Baseline CD4 Count and Adherence to Antiretroviral Therapy: A Systematic Review and Meta-Analysis
}

\author{
Peter Bock, MRCP, MPH, * Anelet James, MSC,* Alliance Nikuze, MMedSc, $\dagger$ \\ Neshaan Peton, Bcur, BTech, MPA, $\ddagger$ Kalpana Sabapathy, MRCP, $\S$ Edward Mills, PhD, MSc,\| \\ Sarah Fidler, FRCP, PhD, I and Nathan Ford, MPH, PhD, FRCPE\#**
}

\begin{abstract}
Background: In light of recent changes to antiretroviral treatment (ART) guidelines of the World Health Organization and ongoing concerns about adherence with earlier initiation of ART, we conducted a systematic review of published literature to review the association between baseline (pre-ART initiation) CD4 count and ART adherence among adults enrolled in ART programs worldwide.

Methods: We performed a systematic search of English language original studies published between January 1, 2004 and September 30, 2015 using Medline, Web of Science, LILACS, AIM, IMEMR, and WPIMR databases. We calculated the odds of being adherent at higher CD4 count compared with lower CD4 count according to study definitions and pooled data using random effects models.
\end{abstract}

Results: Twenty-eight articles were included in the review and 18 in the meta-analysis. The odds of being adherent was marginally lower for patients in the higher CD4 count group (pooled odds ratio, $0.90 ; 95 \%$ confidence interval, 0.84 to 0.96 ); however, the majority of studies found no difference in the odds of adherence when comparing CD4 count strata. In analyses restricted to comparisons above and below a CD4 count of 500 cells per microliter, there was no difference in adherence (pooled odds ratio, 1.01; 95\% confidence interval: 0.97 to 1.05 ).

Received for publication March 12, 2016; accepted May 16, 2016.

From the *Desmond Tutu TB Centre, Department of Paediatrics and Child Health, Stellenbosch University, Stellenbosch, South Africa; †Independent consultant; $\ddagger$ Department of Health, Western Cape Government, Cape Town, South Africa; §London School of Hygiene and Tropical Medicine, London, United Kingdom; \#Precision Global Health, Vancouver, Canada; qDepartment of Medicine, Clinical Trial Units, Imperial College, London, United Kingdom; \#Centre for Infectious Disease Epidemiology and Research, School of Public Health and Family Medicine, University of Cape Town, Cape Town, South Africa; and **Division of infectious diseases, Imperial College London, London, United Kingdom.

The authors have no funding or conflicts of interest to disclose.

P.B., A.N., and A.J. conducted searches. P.B. and N.F. completed the metaanalysis. All authors have contributed to design and development of the manuscript. All authors have approved the version submitted to the journal.

Supplemental digital content is available for this article. Direct URL citations appear in the printed text and are provided in the HTML and PDF versions of this article on the journal's Web site (www.jaids.com).

Correspondence to: Peter Bock, MRCP, MPH, Desmond Tutu TB Centre, Department of Paediatrics and Child Health, Stellenbosch University, Stellenbosch 7925, South Africa (e-mail: peterb@sun.ac.za).

Copyright (C) 2016 Wolters Kluwer Health, Inc. All rights reserved. This is an open-access article distributed under the terms of the Creative Commons Attribution-Non Commercial License 4.0 (CCBY-NC), where it is permissible to download, share, remix, transform, and buildup the work provided it is properly cited. The work cannot be used commercially without permission from the journal.
Conclusions: This review was unable to find consistent evidence of differences in adherence according to baseline CD4 count. Although this is encouraging for the new recommendations to treat all HIV-positive individuals irrespective of CD4 count, there is a need for additional high-quality studies, particularly among adults initiating ART at higher CD4 cell counts.

Key Words: adherence, antiretroviral therapy, CD4 count, HIV

(J Acquir Immune Defic Syndr 2016;73:514-521)

\section{INTRODUCTION}

There are 37 million people living with HIV (PLHIV) and more than 17 million people on antiretroviral treatment (ART) globally. ${ }^{1}$ In 2015, after the publication of findings from 2 large randomized trials indicating the clinical benefit of starting ART at any CD4 cell count, the World Health Organization (WHO) issued updated guidelines recommending that ART should be started in all HIV-infected adults regardless of CD4 count or WHO stage. ${ }^{2-6}$ Current UNAIDS targets for HIV treatment scale-up are for $90 \%$ of PLHIV to know their HIV status, $90 \%$ of those who know their status to be on ART, and $90 \%$ of those on ART to be virally suppressed. ${ }^{7}$ Achieving these targets will require rapid further scale-up of testing and ART initiation and excellent adherence to treatment. Although many factors are known to influence adherence, ${ }^{8}$ one frequently raised concern in the context of new WHO guidelines is the possibility that individuals starting ART at higher CD4 counts when generally clinically well may have lower adherence rates. ${ }^{9,10}$

Although there is strong evidence from individuallevel, randomized, controlled trials for increased patient benefit when routinely initiating ART at CD4 counts greater than 500 cells per microliter, there is limited data informing how ART for all PLHIV will play out in programmatic settings, where the numbers of individuals receiving care and level of resources directed at retaining patients and maximizing adherence is likely to differ from well-resourced randomized trials. Concern has been expressed about potential increases in loss to follow-up, ART nonadherence, sexual disinhibition, and viral resistance among individuals starting treatment earlier, particularly in high-prevalence regions where health facilities are often overburdened. ${ }^{11,12}$

In light of steadily increasing number of adults starting ART at higher CD4 counts when clinically well and recent changes to WHO ART guidelines, we conducted a systematic 
review of the published literature that reported the association between baseline CD4 count and adherence among adult patients enrolled in ART programs worldwide.

\section{METHODS}

\section{Eligibility}

As we were interested in the relationship between baseline CD4 count and adherence in routine program settings, controlled trials were excluded from review. The age of 15 years was used for eligibility because this is the commonly used age cutoff for the management of ART patients at the "adult clinic" for clinical reasons, including drug formulation and dosage. Studies reporting on women starting ART for the prevention of mother-to-child transmission, and use of antiretrovirals for preexposure prophylaxis were also excluded because adherence trends in these populations are not representative of the general population initiating ART. ${ }^{13,14}$

\section{Search Strategy and Study Selection}

This study has been designed and reported according to the Preferred Reporting Items for Systematic Reviews and Meta-Analysis (PRISMA) statement. ${ }^{15}$ We performed a systematic search of English language, original studies published between January 1, 2004 and September 30, 2015 for studies reporting on ART adherence among adults aged $\geq 15$ years according to baseline CD4 count. A limit of January 2004 was used to align with the start of the ART rollout in public health systems in many high-burden countries. Baseline CD4 count was defined as the most recent CD4 count reported before initiating ART and the publishing authors definition of adherence was used for each included study. Medline, Web of Science, LILACS, AIM IMEMR, and WPIMR databases were searched using a compound search strategy incorporating terms for antiretrovirals, adherence, and CD4 count defined in a study protocol (available from the corresponding author). Published abstracts from all Conferences of the International AIDS Society and the Conference on Retroviruses and Opportunistic Infections were searched from 2011 to 2015 to identify data that may have been presented but not yet published in full.

\section{Selection of Studies and Data Extraction}

The primary investigator (P.B.) conducted all searches and reviewed all relevant abstracts, conference presentations,
27 additional articles screened from reference lists

FIGURE 1. Study selection process.

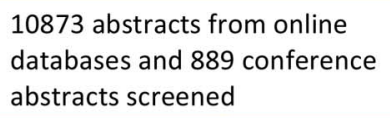

10564 abstracts from full length articles and 884 from conference presentations were excluded as studies did not report on relevant outcomes or meet eligibility criteria

309 full length articles and 5 conference presentations screened

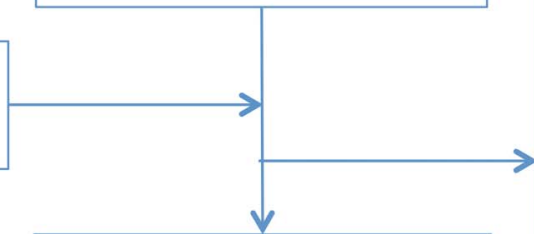

28 articles included in the systematic
308 full length articles and 5 conference presentations excluded

- 293 did not report relevant data

- 8 intervention studies

- 5 included participants $<15$ years

- 1 Adherence measure not clearly defined

- 1 measured adherence to subcutaneous ART 
and full-length articles. All steps in the search process were verified by a second investigator (A.N. or A.J.) (Fig. 1). Disagreements were resolved through consensus. Data extraction followed the same verification procedure, and it included patient and program characteristics according to a predefined data extraction form. Where studies reported both subjective and objectives measures of adherence, the objective measure was used based on the assumption that this was likely to be more accurate. Risk of bias was assessed by the assessment of the following criteria: (1) objective versus subjective adherence measure, (2) baseline differences (other than CD4 count) balanced or adjusted for at analysis, (3) prospective versus retrospective or cross-sectional study design, and (4) and nondifferential loss to follow-up with respect to likelihood of being adherent. We used GRADE to assess the overall quality of the evidence. ${ }^{16}$

\section{Data Analysis}

Our primary effect measure was the odds of being adherent at higher CD4 count compared with lower CD4 count as defined by the studies. Studies that provided raw data on the number of adherent patients or odds ratios (ORs) for adherence by CD4-cell count strata were included in a metaanalysis that estimated ORs and corresponding 95\% confidence intervals (CIs) comparing adherence at lower and higher CD4 counts at baseline; data were pooled using a DerSimonian and Laird ${ }^{17}$ random effects model. Where studies reported multiple CD4 count group comparisons, we included data from the comparison of the lowest and highest CD4 count groups. Where studies reported ORs adjusted for potential confounders, these estimates were used; otherwise, crude estimates were used as indicated in Figure 2. Because the $I^{2}$ statistic does not work well with observational studies, ${ }^{18}$ heterogeneity was assessed by visual inspection of forest plots. Predefined subgroup analyses were run to explore potential differences by income status (as defined by World Bank Income Classification) ${ }^{19}$; we further undertook a post hoc subgroup analysis to assess the potential influence of the 2010 WHO guideline change in treatment eligibility (from CD4 200 cells $/ \mu \mathrm{L}$ to 350 cells $/ \mu \mathrm{L}$ ) by assessing differences before and after 2010. We used STATA version 12.0 (StataCorp LP, College Station, TX) for all analysis. All $P$ values were 2 sided, with a $P$ value less than $0 \cdot 05$ regarded as statistically significant.

\section{RESULTS}

From an initial screen of more than 10,873 abstracts, 27 full-length articles met the inclusion criteria ${ }^{20-46} ; 1$ additional article was identified from bibliography screen, ${ }^{47}$ yielding 28 articles in total included in this review (Fig. 1 and Table 1). The majority of studies (18) were from low-income and middle-income countries. ${ }^{20-22,24,25,27-30,33-35,40-44,46}$ Studies provided data for 72,119 participants, sample sizes ranged from 76 to 3700 adults, with 31,011 men and 40,669 women included ( 1 study did not disaggregate data by sex). ${ }^{46}$ Median baseline CD4 count ranged from 104 to 486 cells per microliter and was
FIGURE 2. Forest plot of the odds of being adherence when comparing patients who started ART in the higher CD4 category with those who start ART in the lower baseline CD4 category.

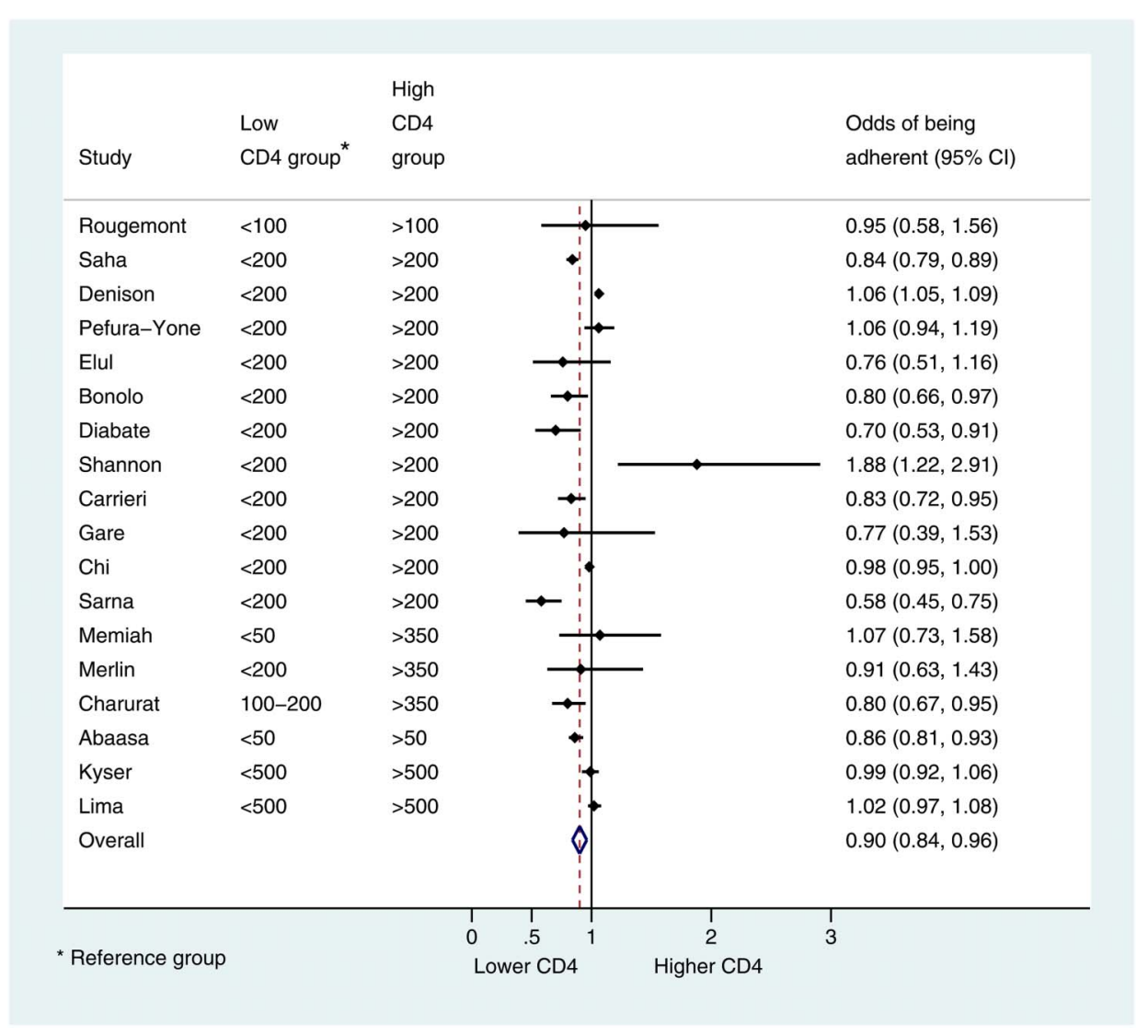


TABLE 1. Overview of Review Studies

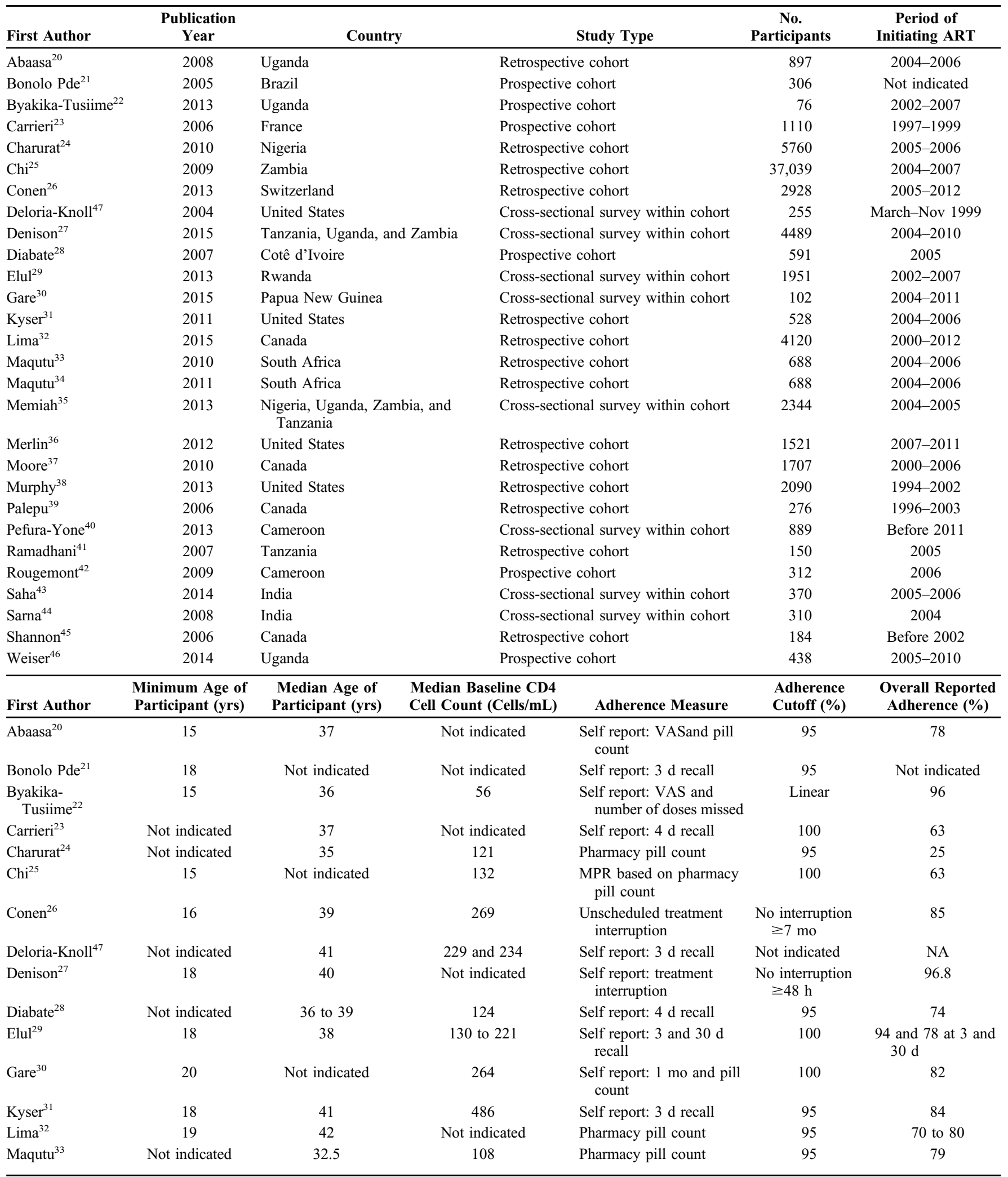


TABLE 1. (Continued) Overview of Review Studies

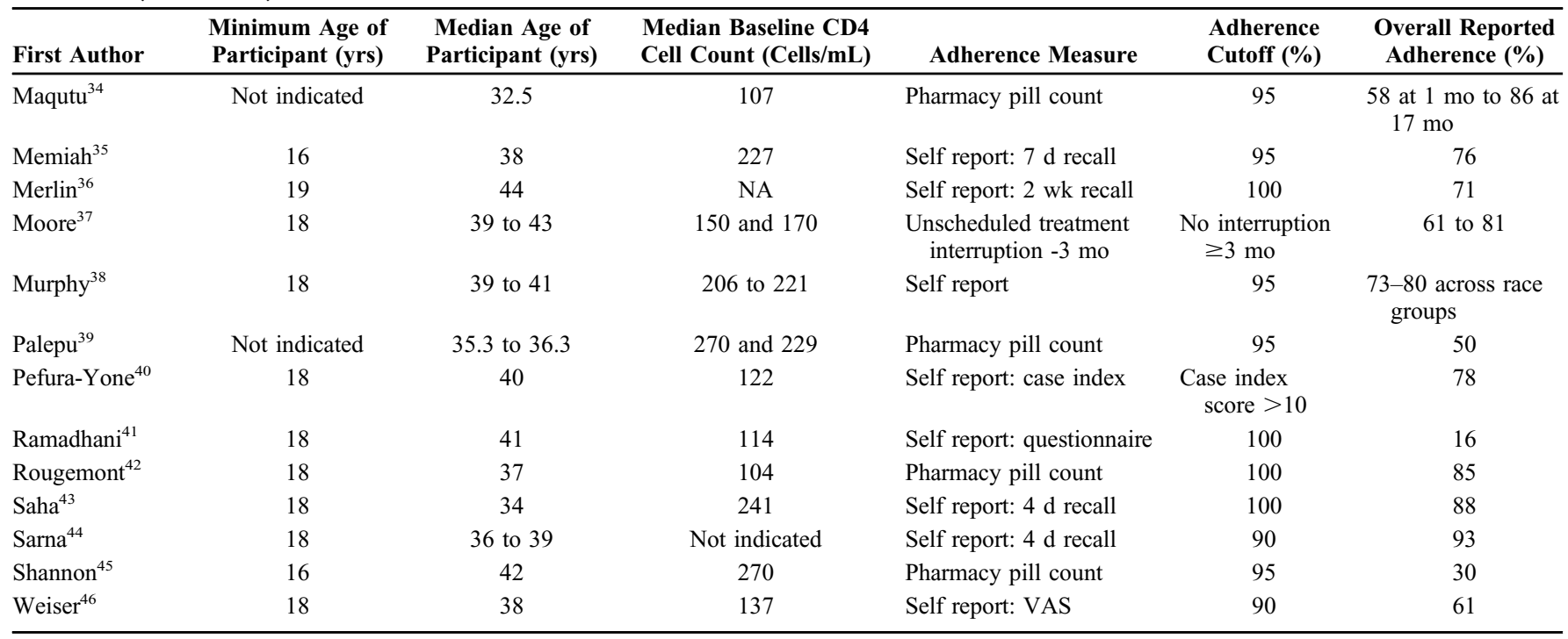

MPR, medicine possession ratio; VAS, visual analogue scale.

$<200$ cells per microliter for 12 studies. $^{21,23,25,27-31,40,43-45}$ Twenty-seven studies reported adherence as a binary outcome and one as a linear outcome, detail of which is presented in Table $1 .{ }^{22}$ Twelve used $<95 \%$ adherence to antiretroviral doses as a threshold for poor adherence, 2 used $<90 \%$, and 8 used $<100 \%$. Three studies reported on unscheduled treatment interruption of 2 days, 7 days, and 3 months, respectively. ${ }^{26,27,37}$ One cross-sectional study used a case index score generated by a questionnaire of greater than " 10 " to generate a binary definition of adherence versus nonadherence (case index score $<10) .{ }^{40}$ None of the studies specifically assessed adherence by CD4 count as the primary outcome.

Studies varied in their reporting of adherence with respect to time on ART. The majority of studies in this review presented multiple pooled estimates of adherence measurements from individuals on ART for durations ranging from 0 to $>7$ years. Two studies reported adherence from initiation to a cutoff time on ART ( 1 month and 6 months). ${ }^{33,42}$ A further 9 studies excluded participants on ART for less than $3,{ }^{24,30}$ $6,{ }^{27,29,41}$ or $12^{23,25,28}$ months of ART. Where studies reported adherence at multiple time points, the data at the measurement taken at the longest duration of ART was used for analysis.

Risk of bias was judged to be moderate based on the characteristics outlined below (see Supplemental Digital Content, http://inks.lww.com/QAI/A841). Retrospective designs (21 studies) and subjective measures of adherence (16 studies) were used most commonly. In the majority (24 studies), baseline differences other than CD4 counts were balanced at baseline or adjusted for in analysis; loss to follow-up was judged to be nondifferential with respect to adherence in 5 of the 10 studies, where the relevant information was provided. Overall, the quality of the evidence was judged to be low.

Eighteen studies provided data on 62,823 participants that could be included in the meta-analysis, ${ }^{20,21,23,24,27-}$ $32,35,36,40,42,44,45,48,49$ among which 11 provided adjusted estimates (Fig. 2)..$^{20,23-25,28,29,31,35,36,42,44}$ Overall, the odds of being adherent was slightly lower for patients in the higher CD4 count group (pooled OR, 0.90; 95\% CI: $0 \cdot 84$ to 0.96 ); however, the majority of studies found no difference in the odds of adherence comparing lower and higher CD4 count strata, and there was little evidence of heterogeneity (Fig. 2). Results were not different when studies were restricted to comparisons above and below a CD4 count of 200 cells per microliter (pooled OR, $0 \cdot 88$; 95\% CI: $0 \cdot 80$ to $0 \cdot 96$ ) compared with higher thresholds. When restricting the analysis to studies reporting adherence above and below 350 cells per microliter, results were again similar to the overall result ( 3 studies; pooled OR, $0 \cdot 85$; $95 \%$ CI: 0.73 to 0.97$)^{24,35,36}$; however, 2 of the 3 studies contributing to this analysis found no difference in adherence. $^{35,36}$ Two studies compared adherence above and below 500 cells per microliter and found no difference in adherence (pooled OR, $1 \cdot 01$; 95\% CI: 0.97 to 1.05 ). ${ }^{31,32}$ Subgroup analysis by income classification found decreased adherence at higher CD4 counts in low-income and middleincome countries (OR, $0.88 ; 95 \% \mathrm{CI}: 0.80$ to 0.96 ), whereas for high-income countries, there was no difference (OR, 0.97; 95\% CI: $0 \cdot 87$ to $1 \cdot 07)$. Studies published before 2010 found decreased adherence at higher CD4 counts (OR, 0.85 ; $95 \%$ CI: 0.76 to 0.93 ), whereas studies published after 2010 found no difference (OR, 0.97; 95\% CI: 0.87 to $1 \cdot 07)$.

Five studies from low-income and middle-income settings, ${ }^{22,33,34,41,46}$ and 5 from high-income settings ${ }^{26,37-39,45}$ provided insufficient data for inclusion in the meta-analysis. Of these, 7 studies presented adjusted ORs of the association between adherence and a numerical baseline CD4 count ${ }^{22,26,33,34,38,39,46}$; one presented adjusted ORs of adherence by median baseline CD4 count $^{41}$ and a further 2 studies ${ }^{37,47}$ presented a crude comparison of median baseline CD4 between adherent and nonadherent 
TABLE 2. Overview of Data From Studies Not Included in the Meta-Analysis

\begin{tabular}{|c|c|c|c|c|c|}
\hline Author & Year & Country & Measure of Baseline CD4 & $\begin{array}{l}\text { Adjusted } \\
\text { Analysis }\end{array}$ & Association With Adherence \\
\hline Deloria-Knoll & 2004 & United States & $\begin{array}{l}\text { Median CD4 count comparison between } \\
\text { adherent and nonadherent groups }\end{array}$ & No & $\begin{array}{l}\text { Mean baseline CD4: adherent group }=378 \\
\text { cells } / \mathrm{mL} \text {. Nonadherent group }=336 \\
\text { cells } / \mathrm{mL} ; P=0.18\end{array}$ \\
\hline Byakika-Tusiime & 2013 & Uganda & Numerical baseline CD4 count & Yes & Adjusted OR, 0.99 (95\% CI: 0.997 to 0.999$)$ \\
\hline Conen & 2013 & Switzerland & $\begin{array}{l}\text { Baseline CD4 cell count per } \\
100 \text { cells } / \mathrm{mL} \text { increase }\end{array}$ & Yes & Adjusted OR, 1.20 (95\% CI: 1.14 to 1.26$)$ \\
\hline Maqutu & 2010 & South Africa & Numerical baseline CD4 count & Yes & Adjusted OR, 0.995 (95\% CI: 0.992 to 0.999$)$ \\
\hline Maqutu & 2011 & South Africa & Numerical baseline CD4 count & Yes & Adjusted OR, 1.000 (95\% CI: 0.998 to 1.001$)$ \\
\hline Moore & 2010 & Canada & $\begin{array}{l}\text { Median CD4 count comparison between } \\
\text { adherent and nonadherent groups }\end{array}$ & No & $\begin{array}{l}\text { Median baseline CD4: adherent group }=150 \\
\text { cells } / \mathrm{mL} \text {. Nonadherent group }=170 \\
\text { cells } / \mathrm{mL} ; P<0.001\end{array}$ \\
\hline Murphy & 2013 & United States & $\begin{array}{l}\text { Baseline CD4 cell count per } \\
100 \text { cells } / \mathrm{mL} \text { increase }\end{array}$ & Yes & Adjusted OR, 1.07 (95\% CI: 1.01 to 1.14 ) \\
\hline Palepu & 2006 & Canada & $\begin{array}{l}\text { Baseline CD } 4 \text { cell count per } \\
100 \text { cells } / \mathrm{mL} \text { increase }\end{array}$ & Yes & Adjusted OR, 0.90 (95\% CI: 0.83 to 0.99$)$ \\
\hline Ramadhani & 2007 & Tanzania & Baseline median CD4 count & Yes & Adjusted OR, $1.0(95 \%$ CI: 1.0 to 1.0$)$ \\
\hline Weiser & 2014 & Uganda & $\begin{array}{l}\text { Baseline CD4 cell count per } \\
100 \text { cells } / \mathrm{mL} \text { increase }\end{array}$ & Yes & Adjusted OR, 0.90 (95\% CI: 0.78 to 1.05$)$ \\
\hline
\end{tabular}

groups. The results of these studies are presented in Table 2. Overall median baseline CD4 count ranged from 56 to 270 cells per microliter, and 6 studies reported a median CD4 count of $<200$ cells per microliter. ${ }^{22,33,34,37,41,46}$ Two studies showed increased adherence with increased CD4 count $(1 \cdot 01$ to $1 \cdot 14$ per 100 cells per microliter increase in baseline CD4 count), ${ }^{26,38} 4$ studies reported a decrease in adherence at higher CD4 count, $^{22,33,37,39}$ and 4 reported no difference. ${ }^{34,41,46,47}$

\section{DISCUSSION}

Overall, the findings of this review showed decreased adherence at higher baseline CD4 count (OR, 0.90; 95\% CI: 0.84 to 0.96 ), although results were inconsistent across studies. Of the 28 studies, 15 showed an individual difference with 11 reporting decreased adherence $e^{20-24,28,33,37,39,43,44}$ and $4^{26,27,38,45}$ reporting increased adherence at higher baseline CD4 count. The odds of being adherent ranged from 0.58 (95\% CI: 0.45 to $0.75)^{44}$ to 1.8 (95\% CI: 1.22 to 2.91$){ }^{45}$ Interpretation of these findings is limited by variability in the definition of higher and lower CD4 count categories between studies. When studies were restricted to a threshold of $>500$ vs $\leq 500$ cells per microliter, no differences were observed.

Reported barriers to adherence are multifactorial. A recent systematic review of the predictors of adherence identified a number of factors associated with adherence, including self-efficacy, substance use, depressive symptoms, concerns about ART, beliefs about the utility of ART, satisfaction with the care provider, stigma, and social support. ${ }^{50}$ Qualitative studies have identified a number of patient-reported barriers to adherence, including forgetfulness, limited understanding of the importance of treatment, drug side effects, pill burden, disruptions to daily routine, and competing priorities. ${ }^{51}$ Some studies have reported that feeling sick is a more frequent barrier to adherence than feeling healthy ${ }^{52}$; this may in part be related to the higher pill burden associated with the treatment of comorbodities. ${ }^{53}$ The relationship between baseline CD4 count and adherence to ART is complex and contextual, and other factors are likely as important or more important in determining adherence, as suggested by the variability in adherence levels between studies included in this review. Although adherence counseling needs to be adapted to respond to the growing number of people starting ART without having experienced an illness event, focusing on any single factor as the cause of poor adherence is unlikely to lead to the necessary support for patients in a way that will lead to optimal health outcomes over time.

Strengths of this review include the comprehensive search of the available literature that allowed us to assess outcomes among over 72,000 adults initiating ART. Nevertheless, the findings of this review are judged to be based on low-quality evidence. This was driven in large part by differences in CD4 count thresholds and adherence definitions applied between studies, which to a degree reflect differences in ART initiation thresholds applied in different settings. We present forest plots to display between-study heterogeneity and used random effects models. Another limitation with respect to informing current ART guideline changes is that many of the studies included in this review were done at a time when ART was initiated at a low threshold of CD4 count 200 or 350 cells per microliter. ${ }^{2}$ In such settings, patients initiating ART at higher CD4 counts represent specific patient populations (eg, pregnant women or tuberculosis-HIV coinfected patients) who may not be representative of the broader patient population, and only 4 studies adjusted for the presence of WHO defining illness at ART initiation in the analysis of adherence..$^{23,25,40,42}$ Duration of ART may also be an important factor affecting adherence, although this relationship was inconsistent with some studies showing an increased adherence over time s4 $^{54}$ and some showing a decreased adherence. ${ }^{24,32}$ Therefore, a further 
important limitation is the marked heterogeneity and the lack of reporting of the duration on ART at which adherence was measured.

In conclusion, this review was unable to find strong evidence supporting consistent differences in adherence according to baseline CD4 count, particularly at CD4 counts $>500$ cells per microliter. Although this may be encouraging for the implementation of the new WHO ART guidelines, the quality of the limited published evidence to date is variable. Further studies with improved standardization of methods for monitoring and reporting ART adherence are therefore encouraged as HIV programs shift toward starting treatment irrespective of immune status.

\section{REFERENCES}

1. UNAIDS. Global AIDS Update 2016. Geneva, Switzerland: UNAIDS; 2016.

2. Gupta S, Granich R, Suthar AB, et al. Global policy review of antiretroviral therapy eligibility criteria for treatment and prevention of HIV and tuberculosis in adults, pregnant women, and serodiscordant couples. J Acquir Immune Defic Syndr. 2013;62:e87-e97.

3. World Health Organisation. Consolidated Guidelines for the Use of Antiretroviral Drugs for Treating and Preventing HIV Infection. Reccomendations for a Public Health Approach. Geneva, Switzerland: World Health Organisation; 2013.

4. Lundgren JD, Babiker AG, Gordin F, et al. Initiation of antiretroviral therapy in early Asymptomatic HIV infection. N Engl J Med. 2015;373: 795-807.

5. Danel C, Moh R, Gabillard D, et al. A trial of early antiretrovirals and Isoniazid preventive therapy in Africa. N Engl J Med. 2015;373:808822.

6. World Health Organization. Guideline on When to Start Antiretroviral Therapy and on Pre-exposure Prophylaxis for HIV. Geneva, Switzerland: World Health Organization; 2015.

7. UNAIDS. 90-90-90-An Ambitious Treatment Target to Help End the AIDS Epidemic. Geneva, Switzerland: UNAIDS; 2014. http://www. unaids.org/en/resources/documents/2014/90-90-90.

8. Mills EJ, Nachega JB, Buchan I, et al. Adherence to antiretroviral therapy in sub-Saharan Africa and North America: a meta-analysis. JAMA. 2006; 296:679-690

9. Goldman JD, Cantrell RA, Mulenga LB, et al. Simple adherence assessments to predict virologic failure among HIV-infected adults with discordant immunologic and clinical responses to antiretroviral therapy. AIDS Res Hum Retroviruses. 2008;24:1031-1035.

10. Glass TR, Rotger M, Telenti A, et al. Determinants of sustained viral suppression in HIV-infected patients with self-reported poor adherence to antiretroviral therapy. PLoS One. 2012;7:e29186.

11. Lockman S, Sax P. Treatment-for-prevention: clinical considerations. Curr Opin HIV AIDS. 2012;7:131-139.

12. Cornell M, Grimsrud A, Fairall L, et al. Temporal changes in programme outcomes among adult patients initiating antiretroviral therapy across South Africa, 2002-2007. AIDS. 2010;24:2263-2270.

13. Hodgson I, Plummer ML, Konopka SN, et al. A systematic review of individual and contextual factors affecting ART initiation, adherence, and retention for HIV-infected pregnant and postpartum women. PLoS One. 2014;9:e111421

14. Fidler S, Bock P. Prophylactic antiretroviral HIV therapy prevents infection in heterosexual men and women. Evid Based Med. 2013;18:184-185.

15. Moher D, Shamseer L, Clarke M, et al. Preferred reporting items for systematic review and meta-analysis protocols (PRISMA-P) 2015 statement. Syst Rev. 2015;4:1

16. Guyatt GH, Oxman AD, Vist GE, et al. GRADE: an emerging consensus on rating quality of evidence and strength of recommendations. BMJ. 2008;336:924-926.

17. DerSimonian R, Laird N. Meta-analysis in clinical trials. Control Clin Trials. 1986;7:177-188.

18. Mills EJ, Jansen JP, Kanters S. Heterogeneity in meta-analysis of FDGPET studies to diagnose lung cancer. JAMA. 2015;313:419.
19. The World Bank. Country and Lending Groups. Washington DC; 2016.

20. Abaasa AM, Todd J, Ekoru K, et al. Good adherence to HAART and improved survival in a community HIV/AIDS treatment and care programme: the experience of the AIDS Support Organization (TASO), Kampala, Uganda. BMC Health Serv Res. 2008;8:241.

21. Bonolo Pde F, Cesar CC, Acurcio FA, et al. Non-adherence among patients initiating antiretroviral therapy: a challenge for health professionals in Brazil. AIDS. 2005;19(suppl 4):S5-S13.

22. Byakika-Tusiime J, Polley EC, Oyugi JH, et al. Free HIV antiretroviral therapy enhances adherence among individuals on stable treatment: implications for potential shortfalls in free antiretroviral therapy. PLoS One. 2013;8:e70375.

23. Carrieri MP, Leport C, Protopopescu C, et al. Factors associated with nonadherence to highly active antiretroviral therapy: a 5-year follow-up analysis with correction for the bias induced by missing data in the treatment maintenance phase. J Acquir Immune Defic Syndr. 2006;41: $477-485$.

24. Charurat M, Oyegunle M, Benjamin R, et al. Patient retention and adherence to antiretrovirals in a large antiretroviral therapy program in Nigeria: a longitudinal analysis for risk factors. PLoS One. 2010;5: e10584.

25. Chi BH, Cantrell RA, Zulu I, et al. Adherence to first-line antiretroviral therapy affects non-virologic outcomes among patients on treatment for more than 12 months in Lusaka, Zambia. Int J Epidemiol. 2009;38: 746-756.

26. Conen A, Wang Q, Glass TR, et al. Association of alcohol consumption and HIV surrogate markers in participants of the swiss HIV cohort study. J Acquir Immune Defic Syndr. 2013;64:472-478.

27. Denison JA, Koole O, Tsui $\mathrm{S}$, et al. Incomplete adherence among treatment-experienced adults on antiretroviral therapy in Tanzania, Uganda and Zambia. AIDS. 2015;29:361-371.

28. Diabate S, Alary M, Koffi CK. Determinants of adherence to highly active antiretroviral therapy among HIV-1-infected patients in Cote d'Ivoire. AIDS. 2007;21:1799-1803.

29. Elul B, Basinga P, Nuwagaba-Biribonwoha H, et al. High levels of adherence and viral suppression in a nationally representative sample of HIV-infected adults on antiretroviral therapy for 6, 12 and 18 months in Rwanda. PLoS One. 2013;8:e53586.

30. Gare J, Kelly-Hanku A, Ryan CE, et al. Factors influencing antiretroviral adherence and virological outcomes in people living with HIV in the Highlands of Papua New Guinea. PLoS One. 2015;10:e0134918.

31. Kyser M, Buchacz K, Bush TJ, et al. Factors associated with nonadherence to antiretroviral therapy in the SUN study. AIDS Care. 2011; 23:601-611.

32. Lima VD, Reuter A, Harrigan PR, et al. Initiation of antiretroviral therapy at high CD4+ cell counts is associated with positive treatment outcomes. AIDS. 2015;29:1871-1882.

33. Maqutu D, Zewotir T, North D, et al. Factors affecting first-month adherence to antiretroviral therapy among HIV-positive adults in South Africa. Afr J AIDS Res. 2010;9:117-124.

34. Maqutu D, Zewotir T, North D, et al. Determinants of optimal adherence over time to antiretroviral therapy amongst HIV positive adults in South Africa: a longitudinal study. AIDS Behav. 2011;15:1465-1474

35. Memiah P, Shumba C, Etienne-Mesubi M, et al. The effect of depressive symptoms and CD4 count on adherence to highly active antiretroviral therapy in sub-Saharan Africa. J Int Assoc Provid AIDS Care. 2013;13: 346-352.

36. Merlin JS, Westfall AO, Raper JL, et al. Pain, mood, and substance abuse in HIV: implications for clinic visit utilization, antiretroviral therapy adherence, and virologic failure. J Acquir Immune Defic Syndr. 2012;61: 164-170.

37. Moore DM, Zhang W, Yip B, et al. Non-medically supervised treatment interruptions among participants in a universally accessible antiretroviral therapy programme. HIV Med. 2010;11:299-307.

38. Murphy K, Hoover DR, Shi Q, et al. Association of self-reported race with AIDS death in continuous HAART users in a cohort of HIV-infected women in the United States. AIDS. 2013;27: 2413-2423.

39. Palepu A, Tyndall MW, Joy R, et al. Antiretroviral adherence and HIV treatment outcomes among $\mathrm{HIV} / \mathrm{HCV}$ co-infected injection drug users: the role of methadone maintenance therapy. Drug Alcohol Depend. 2006; 84:188-194.

Copyright (C) 2016 Wolters Kluwer Health, Inc. All rights reserved. 
40. Pefura-Yone EW, Soh E, Kengne AP, et al. Non-adherence to antiretroviral therapy in Yaounde: prevalence, determinants and the concordance of two screening criteria. J Infect Public Health. 2013;6: $307-315$.

41. Ramadhani HO, Thielman NM, Landman KZ, et al. Predictors of incomplete adherence, virologic failure, and antiviral drug resistance among HIV-infected adults receiving antiretroviral therapy in Tanzania. Clin Infect Dis. 2007;45:1492-1498.

42. Rougemont M, Stoll BE, Elia N, et al. Antiretroviral treatment adherence and its determinants in sub-Saharan Africa: a prospective study at Yaounde Central hospital, Cameroon. AIDS Res Ther. 2009;6:21.

43. Saha R, Saha I, Sarkar AP, et al. Adherence to highly active antiretroviral therapy in a tertiary care hospital in West Bengal, India. Singapore Med J. 2014;55:92-98.

44. Sarna A, Pujari S, Sengar AK, et al. Adherence to antiretroviral therapy $\&$ its determinants amongst HIV patients in India. Indian $J$ Med Res. 2008;127:28-36.

45. Shannon K, Kerr T, Lai C, et al. Nonadherence to antiretroviral therapy among a community with endemic rates of injection drug use. J Int Assoc Physicians AIDS Care (Chic). 2005;4:66-72.

46. Weiser SD, Palar K, Frongillo EA, et al. Longitudinal assessment of associations between food insecurity, antiretroviral adherence and HIV treatment outcomes in rural Uganda. AIDS. 2014;28:115-120.

47. Deloria-Knoll M, Chmiel JS, Moorman AC, et al. Factors related to and consequences of adherence to antiretroviral therapy in an ambulatory
HIV-infected patient cohort. AIDS Patient Care STDs. 2004;18: 721-727.

48. Abdool Karim SS, Churchyard GJ, Abdool Karim Q, et al. HIV infection and tuberculosis in South Africa: an urgent need to escalate the public health response. Lancet. 2009;374:921-933.

49. Bemelmans M, Baert S, Goemaere E, et al. Community-supported models of care for people on HIV treatment in sub-Saharan Africa. Trop Med Int Health. 2014;19:968-977.

50. Langebeek N, Gisolf EH, Reiss P, et al. Predictors and correlates of adherence to combination antiretroviral therapy (ART) for chronic HIV infection: a meta-analysis. BMC Med. 2014;12:142.

51. Mills EJ, Nachega JB, Bangsberg DR, et al. Adherence to HAART: a systematic review of developed and developing nation patient-reported barriers and facilitators. PLoS Med. 2006;3:e438.

52. Saberi P, Neilands TB, Vittinghoff E, et al. Barriers to antiretroviral therapy adherence and plasma HIV RNA suppression among AIDS clinical trials group study participants. AIDS Patient Care STDs. 2015; 29:111-116.

53. Nachega JB, Parienti JJ, Uthman OA, et al. Lower pill burden and oncedaily antiretroviral treatment regimens for HIV infection: a meta-analysis of randomized controlled trials. Clin Infect Dis. 2014;58:1297-1307.

54. Bijker J, Jiamsakul A, Siwale M, et al. Determinants of adherence to antiretroviral therapy differ between Africa and Asia. Conference on Retroviruses and Opportunistic Infections (CROI), February 23-26, 2015; Seattle, WA. 